\title{
A sociolinguística para além das variáveis sociais: a promoção de justiça social
}

\author{
Marta Deysiane Alves Faria SOUSA (1) \\ Universidade Federal de Sergipe (UFS)
}

Paloma Batista CARDOSO

OPEN ACCESS

Universidade Federal de Sergipe (UFS)

EDITADO POR

Raquel Freitag

AVALIADO POR

Livia Oushiro

SOBRE OS AUTORES

Marta Deysiane Alves

Faria Sousa

Contribuiu com Paloma Batista

Cardoso. Papéis:

conceptualização, visualização,

escrita - rascunho original,

análise e edição.

Paloma Batista Cardoso Contribuiu com Marta Deysiane

Alves Faria Sousa. Papéis conceptualização, visualização,

escrita - rascunho original, análise e edição.

DATAS

Recebido: 26/05/2020 Aceito: $25 / 07 / 2020$ Publicado: 10/08/2020

COMO CITAR Sousa, M. D. A. F.; Cardoso, P. B. (2020). A sociolinguística para além das variáveis sociais: a promoção de justiça social. Revista da Abralin, v. 19, n. 2, p.

\section{RESUMO}

Neste texto, resenhamos a conferência intitulada Language as a linguistic matter, ministrada por William Labov no evento Abralin ao vivo em 19 de maio de 2020. Labov discorre sobre as contribuições do estudo da variação do /r/ em Nova Iorque e a descrição do African American Vernacular English (AAVE) para a pesquisa sociolinguística. Segundo o conferencista, a partir desses trabalhos foi possível desenvolver novos métodos de descrição e análise quantitativa dos fatores linguísticos e sociais que atuam nos processos de variação e mudança linguística. Labov aponta como os estudos descritivos podem ser úteis às esferas educacional e jurídica, promovendo um ensino de língua eficiente e atuando como ferramenta para a promoção de justiça social.

\section{ABSTRACT}

In this text, we review the lecture entitled Language as a linguistic matter, delivered by William Labov at Abralin Linguists Online event on May $19^{\text {th }}$, 2020. Labov discusses the contributions of the study on / $/ \mathrm{v}$ variation in New York City, and the description of African American Vernacular English (AAVE) for sociolinguistic research. According to the lecturer, these works made it possible to develop new methods of description and quantitative analysis of linguistic and social factors in play in the processes of language variation and change. Labov argues that descriptive studies can be useful in the educational and legal spheres, promoting efficient language teaching and acting as a tool for the promotion of social justice. 


\section{REVISTA DA ABRALIN}

PALAVRAS-CHAVE

Variação linguística. Sociolinguística. Justiça social.

\section{KEYWORDS}

Linguistic variation. Sociolinguistics. Social Justice.

Neste texto, resenhamos a conferência Justiça como uma questão linguística proferida por William Labov no evento Abralin Ao Vivo, no dia 19 de maio de 2020. A princípio, Labov afirma que o tema de sua conferência tem origem na avaliação de seu trabalho pelo comitê da Associação Americana de Artes e Ciências, que o agraciou com o prêmio Talcott Parsons devido às contribuições para os estudos de variação e mudança linguística, o desenvolvimento da linguística como ciência, bem como a sua preocupação com a justiça social. O conferencista, então, delimita o objetivo de sua fala: demonstrar como o estudo da variação linguística pode contribuir para a promoção de justiça social, uma relação que, conforme Labov, à primeira vista não é tão evidente.

O conferencista discute o fato de que embora seu trabalho seja reconhecido pelos esforços para tentar melhorar o letramento entre falantes de variedades estigmatizadas, a relação entre o estudo quantitativo de variáveis linguísticas e a justiça social não é clara. Por exemplo, sabe-se que o apagamento do /r/ pós-vocálico, um traço característico do inglês falado pelos nova-iorquinos é estigmatizado, mas esse não é um fator que causa prejuízos sociais aos falantes. Todavia, o mesmo não acontece com afro-americanos, falantes de uma variedade linguística considerada não-padrão.

No estudo realizado no Lower East Side, que teve como objetivo investigar traços fonológicos variáveis, como o apagamento do /r / pós-vocálico entre os falantes dessa região (LABOV, 2006, p. $97)^{1}$, apenas $24 \%$ dos participantes eram afro-americanos. Por isso, não havia razão para acreditar que esse percentual representava $100 \%$ dos falantes dessa etnia. Isso levou o conferencista a buscar fundos para fazer uma ampla análise linguística do inglês não-padrão. Nos exames de leitura, elaborados com base na variedade padrão do inglês, os afro-americanos apresentavam rendimento insatisfatório. Por isso, Labov se propôs a verificar se existia uma conexão entre a variedade linguística desses falantes e o baixo rendimento dos alunos nas escolas do Harlem. Para tal, o pesquisador utilizou uma metodologia similar à do Lower East Side.

Para estudar o inglês afro-americano, doravante AAVE (do inglês African American Vernacular English), Labov, com a ajuda de dois falantes do Harlem, executou gravações individuais e com os grupos de rua: cobras, jets e thunderbirds. A característica da fala que mais chamou a atenção foi a realização da cópula ( $a m$, is ou are) que poderia aparecer de forma contraída, não contraída (That's

10 modelo de estratificação desse estudo bem como o roteiro que estruturou as entrevistas sociolinguísticas foram elaborados com base na Mobilization for Youth (MFY), survey em larga escala constituída por perguntas abertas sobre aspirações sociais, participação na comunidade, atitudes em relação à vizinhança e à delinquência juvenil. 


\section{REVISTA DA ABRALIN}

what he is: a brother) ou apagada (But everybody Ø not black) no AAVE. Labov constatou que as variedades padrão do inglês e o AAVE compartilham a mesma estrutura: nos casos em que a variedade padrão permite contração da cópula, o AAVE apaga ("He Ø fast in everything he do", exemplo de apagamento da cópula no AAVE, quando na variante padrão poderia ser contraída "'s"); nos contextos em que a variedade padrão não permite contração, o AAVE não permite apagamento (na variedade padrão, a seguinte construção não ocorre "He's as nice as he says he's", logo, no AAVE, a construção "He's as nice as he says he" também não é possível).

A realização da cópula no AAVE não é aleatória: a frequência da contração ou apagamento é determinada pelos antecedentes e subsequentes gramaticais (ocorrência menor antes de sintagmas nominais e maior antes de adjetivos, locativos, verbos e construções de futuro com o going to). Além dos fatores internos à estrutura linguística, o pesquisador verificou que a idade e a história social também influenciam o comportamento linguístico dos falantes, o que foi percebido em estudos realizados em outras localidades dos Estados Unidos.

Apesar das evidências de que a variedade padrão do inglês e o AAVE compartilham a mesma estrutura, essas análises não eram absorvidas pelos psicólogos educacionais. Bereiter e Engelman, por exemplo, afirmaram que o AAVE era ilógico e que, por serem privados de cultura, os afro-americanos falariam uma versão subdesenvolvida do inglês padrão, utilizado pelos brancos. Nesse sentido, se as crianças do Harlem respondessem à pergunta "Where is the squirrel?" ("Onde está o esquilo?") em seu vernáculo, "In the tree." ("Na árvore.”), seriam repreendidas, porque essa não seria uma resposta lógica, pois a escola lhes ensina a responder de acordo com a variedade padrão: "The squirrel is in the tree." ("O esquilo está na árvore."). É este peso social atribuído ao AAVE e aos seus falantes que, para Labov, carece de justiça social.

Uma das tentativas de Labov de promover justiça social ao AAVE e aos seus falantes foi a publicação do artigo The logic of non-standard English. Dentre os dados de fala analisados nesse artigo, o conferencista expõe um excerto de uma entrevista em que há vários exemplos de traços do AAVE:

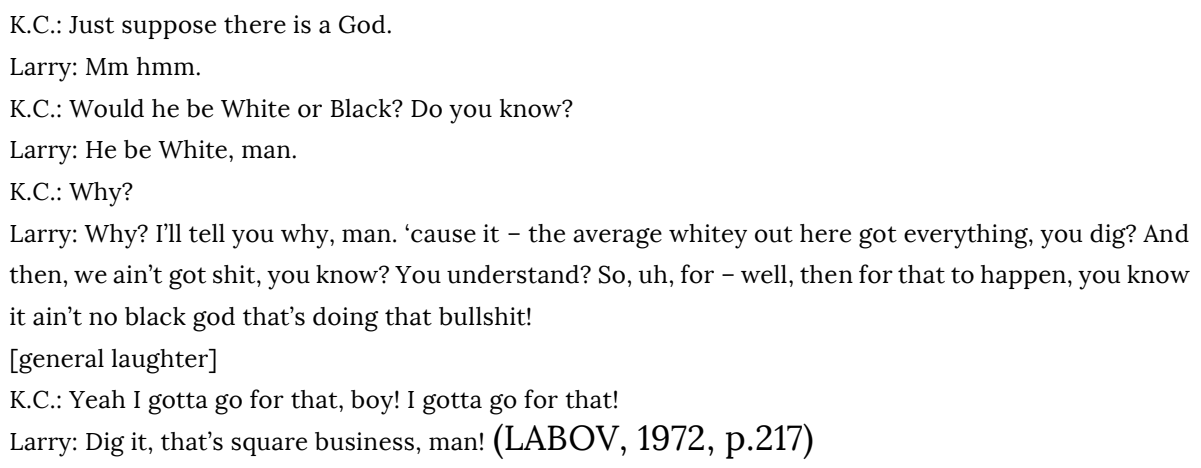




\section{REVISTA DA ABRALIN}

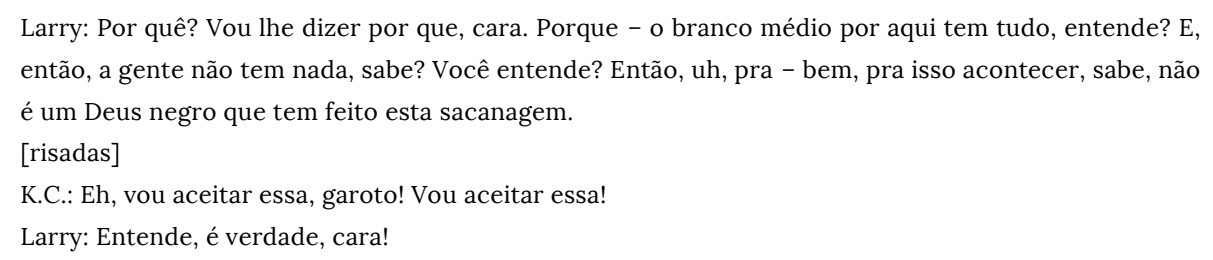

Nesse excerto há diferentes exemplos do AAVE que sugerem que, apesar de não estarem de acordo com o inglês padrão, sua ocorrência apresenta uma lógica subjacente: o "it" utilizado no lugar do sujeito-indeterminado "there", a presença da cópula "ain't", e o reforço da negativa com "no". Segundo Labov, esses exemplos por si só não refletem necessidade de justiça, mas o julgamento a eles atribuído e suas consequências, sim.

O tratamento inadequado conferido às diferenças entre o AAVE e o inglês padrão tem resultados catastróficos no que diz respeito ao ensino de leitura e, consequentemente, na mobilidade e ascensão social. Para ilustrar esse fato, Labov cita o The Ann Arbor Trial. Na década de 1970, em Michigan, devido às dificuldades de aprendizagem de leitura, crianças afrodescendentes foram ameaçadas de exclusão ou excluídas das aulas regulares, sendo colocadas em salas para pessoas com algum tipo de deficiência cognitiva. Ao depor no processo movido pelos pais das crianças contra as autoridades escolares, a Professora Geneva Smitherman, da Universidade Estadual de Wayne, comparou dados de fala da comunidade negra de Ann Arbor com os dados do estudo de Labov no Harlem, encontrando o mesmo padrão, mostrando a lógica do AAVE bem como seu padrão estrutural. Esse fato levou o juiz Charles Joiner, responsável pelo caso, a sentenciar as autoridades escolares a criarem um plano de ensino capaz de identificar os falantes do AAVE e mobilizar conhecimentos para ensinálos a ler o inglês padrão, superando assim qualquer barreira linguística que pudesse causar prejuízos sociais aos alunos. Labov afirmou que não houve muito progresso a partir das medidas indicadas pelo juiz Joiner, uma vez que a comunidade geral não entendeu a visão linguística da variedade AAVE, o que foi confirmado pelo caso Ebonics ${ }^{2}$, em Oakland.

Os estudos que descrevem padrões de variação linguística são feitos a partir de entrevistas sociolinguísticas. Por meio delas, o pesquisador adquire não só dados como também conhecimentos sobre cada falante e sua realidade. Há, nessa situação, uma troca. Por isso, Labov afirma que a descrição linguística deve ser pautada pelo "Princípio do Débito Incorrido". Nesse sentido, o conhecimento construído por meio dos dados deve, por obrigação, ser devolvido à comunidade quando ela dele precisar. Embora tenha dedicado seu livro Language in the Inner City aos grupos de rua que participaram da pesquisa no Harlem, o conferencista não havia conseguido dar um retorno àquela comunidade.

Ao verificar que a situação de algumas localidades da Filadélfia era similar às do Harlem - o desempenho na leitura de falantes afro-americanos era insatisfatório - Labov resolveu, com o apoio da Universidade da Pensilvânia e da Fundação Nacional de Ciências, desenvolver um projeto de

$2 \mathrm{O}$ caso Ebonics se refere ao fato de que as autoridades escolares de Oakland decidiram reconhecer o Ebonics como a língua materna das crianças afro-americanas, e essa decisão foi hostilizada pela sociedade e imprensa (RICKFORD, 1999). 


\section{REVISTA DA ABRALIN}

tutoria para ensinar as crianças como o alfabeto funciona dentro de um panorama que engloba a relação entre o AAVE e o mundo, envolvendo segregação e racismo institucionalizado. O principal instrumento desse projeto é o material de leitura em formato de graphic novel intitulado The Reading Road, baseado em histórias contadas por falantes do AAVE do Harlem. Nesse material, conforme relatado pelo conferencista, há uma história chamada Take off your coat, na qual um aluno acabou de castigo na escola injustamente.

Para Labov, The Reading Road apresenta o mundo como os falantes do AAVE o conhecem: injusto e segregador. O pesquisador argumenta ainda que o material, ao aproximar-se da realidade dos estudantes, tem o poder de convencê-los de que eles podem aprender a ler mesmo que não sejam "criancinhas boazinhas". A prática de The Reading Road é pautada na realidade dos alunos afro-americanos, a partir de um modelo de ensino de leitura que, para ser bem sucedido, considera a variedade de fala deles. Assim, constitui uma forma de promoção de justiça social no âmbito educacional, a fim de possibilitar que, ao lerem satisfatoriamente, os alunos tenham maiores chances de mobilidade social.

Labov sinaliza que a esfera educacional não é a única para a qual os estudos descritivos podem ser úteis. Para além da descrição de padrões de fala do AAVE e a comprovação de que essa variedade é lógica e compartilha a mesma estrutura com a variedade padrão, e da promoção de justiça social por vias educacionais e jurídicas, o avanço no método quantitativo de análise linguística permitiu a elaboração do Atlas of North American English, do qual Labov é um dos autores. Na década de 1990, mais de 50.000 entrevistas gravadas por telefone foram feitas, com pelo menos duas pessoas por cidade dos Estados Unidos e Canadá. A análise acústica de amostras de fala de todos esses participantes comprovou casos de mudança: fusão de duas vogais e rotação de vogais, sinalizando a influência de variáveis linguísticas e sociais no processo de variação e mudança linguística.

Dados sobre diferenças dialetais como os do Atlas of North American English, embora aparentemente sem consequência para a vida das pessoas, foram cruciais para que a justiça fosse feita com um cidadão norte-americano, Paul Prinzivalli, que, em 1984, foi preso sob acusação de ameaças de bomba à companhia aérea Pan American. A situação de Prinzivalli era um caso de identificação de voz: nos áudios de ameaça, ouvia-se alguém com traços fonéticos característicos do sudeste da Nova Inglaterra, enquanto o acusado era um falante tipicamente nova-iorquino. As diferenças entre os aspectos fonológicos dessas duas variedades foram apontadas por Labov no tribunal, e, graças ao registo do Atlas of North American English e o desenvolvimento de técnicas de análise física dos sons, Prinzivalli foi inocentado.

No final de sua fala, Labov explicita aquilo que permeou toda a conferência - e, principalmente, toda a sua prática enquanto sociolinguista: a importância de se ouvir o informante e compreendêlo, não apenas gravá-lo. A fala evidencia não só padrões fonéticos e estruturais, mas também sinaliza aspectos sociais referentes aos lugares ocupados pelos falantes na sociedade. Labov finaliza sua conferência afirmando que o estudo quantitativo deve dar voz aos falantes evidenciando suas necessidades, em uma tentativa de tornar o mundo um pouco mais justo do que é.

A importância de se ouvir o informante norteou toda a discussão que seguiu a fala do conferencista. A audiência reafirmou a importância do fazer sociolinguístico como uma prática de justiça social, 


\section{REVISTA DA ABRALIN}

o que no Brasil tem sido feito sobretudo por meio da sociolinguística educacional. Além disso, destacou-se que a relação de prestígio e estigma entre o inglês padrão e o não-padrão é semelhante à existente entre o português padrão e o chamado "pretoguês". Labov acredita que esta relação acontece devido à concepção errônea de que as línguas se originam de uma única forma, que é reconhecida como correta; e que tudo aquilo que difere desse padrão inicial reflete um processo de deterioração.

Por ser um pesquisador cujos trabalhos possuem importância mundial, a audiência da conferência foi composta por pessoas de diferentes países. O fato de as pesquisas sociolinguísticas normalmente reportarem dados majoritariamente advindos de países do ocidente foi pontuado por um participante da Ásia. Labov argumentou que os métodos descritos na conferência contribuem para uma estratificação vertical das estruturas sociais, porém, a relação entre as línguas faladas na Ásia e seus falantes deve ser estudada nos contextos sociais específicos, uma vez que, por exemplo, questões de gênero são distintas em diferentes línguas. O pesquisador reafirmou que estudos comparativos entre múltiplas línguas, por exemplo, podem se beneficiar muito ao observarem uma compreensão de classes sociais e gênero específicos de suas comunidades.

A reflexão empreendida por Labov, desde o título da conferência, Justiça como uma questão linguística, enfatiza a nossa função na sociedade enquanto linguistas: a partir da descrição quantitativa dos padrões da fala de diferentes grupos, sejam eles privilegiados ou não, fazer com que os falantes sejam ouvidos, de modo a tornar o mundo um pouco mais justo.

\section{REFERÊNCIAS}

JUSTICE as a linguistic matter. Conferência apresentada por William Labov. [s.l., s.n], 2020. 1 vídeo (1h 06min 33s). Publicado pelo canal da Associação Brasileira de Linguística. Disponível em: https://www.youtube.com/watch?v=hqrsHmhcrSQ. Acesso em: 23 maio 2020.

LABOV, William. The social stratification of English in New York city. Cambridge University Press, 2006.

LABOV, William; ASH, Sharon; BOBERG, Charles. The Atlas of North American English: Phonetics, phonology and sound change. Berlin: Mouton/de Gruyter, 2006.

LABOV, William. Language in the inner city: Studies in the Black English Vernacular. Philadelphia: University of Philadelphia Press Cambridge University Press, 2006.

RICKFORD, John. The Ebonics controversy in my backyard: A sociolinguist's experiences and reflections. 1999. Disponível em: https://web.stanford.edu/ rickford/papers/EbonicsInMyBackyard.html. Acesso em: 24 maio 2020.

THE reading road. Disponível em: https://web.sas.upenn.edu/penn-reading/tutoring-curriculum/the-reading-road/. Acesso em: 23 maio 2020. 